\title{
Overexpression of miR-221 and miR-222 in the cancer stroma is associated with malignant potential in colorectal cancer
}

\author{
MICHIHISA IIDA ${ }^{1}$, SHOICHI HAZAMA ${ }^{1,2}$, RYOUICHI TSUNEDOMI ${ }^{1}$, HIRONORI TANAKA ${ }^{1}$, \\ HIROKO TAKENOUCHI $^{1}$, SHINSUKE KANEKIYO ${ }^{1}$, YUKIO TOKUMITSU ${ }^{1}$, SHINOBU TOMOCHIKA ${ }^{1}$, \\ YOSHIHIRO TOKUHISA ${ }^{1}$, KAZUHIKO SAKAMOTO ${ }^{1}$, NOBUAKI SUZUKI ${ }^{1}$, SHIGERU TAKEDA ${ }^{1}$, \\ TOMIO UENO $^{3}$, SHIGERU YAMAMOTO ${ }^{1}$, SHIGEFUMI YOSHINO ${ }^{1,4}$, KOJI FUJTTA ${ }^{5}$, \\ MASAHIKO KURODA $^{5}$ and HIROAKI NAGANO ${ }^{1}$ \\ ${ }^{1}$ Department of Gastroenterological, Breast and Endocrine Surgery; \\ ${ }^{2}$ Department of Translational Research and Developmental Therapeutics against Cancer, \\ Yamaguchi University School of Medicine, Ube, Yamaguchi 755-8505; ${ }^{3}$ Department of Digestive Surgery, \\ Kawasaki Medical School, Kurashiki, Okayama 701-0192; ${ }^{4}$ Oncology Center, Yamaguchi University Hospital, Ube, \\ Yamaguchi 755-8505; ${ }^{5}$ Department of Molecular Pathology, Tokyo Medical University, Tokyo 160-8402, Japan
}

Received January 28, 2018; Accepted June 18, 2018

DOI: $10.3892 / o r .2018 .6575$

\begin{abstract}
The cancer stroma is important in cancer development, however, whether the aberrant expression of microRNAs (miRNAs) in the cancer stroma is associated with cancer progression remains to be fully elucidated. The aim of the present study was to identify the miRNAs associated with liver metastasis in the cancer stroma of human colorectal cancer (CRC). Using laser capture microdissection, cancer stroma was obtained from the primary lesion of six patients with CRC with liver metastasis (CRCwLM) and six patients with CRC without liver metastasis (CRCwoLM), and miRNA microarray analysis was performed. Candidate miRNA expression status in the stroma was validated by reverse transcription-quantitative polymerase chain reaction (RT-qPCR) analysis in $40 \mathrm{CRC}$ cases (wLM, n=20; woLM, n=20), and the association between
\end{abstract}

Correspondence to: Professor Hiroaki Nagano, Department of Gastroenterological, Breast and Endocrine Surgery, Yamaguchi University School of Medicine, 1-1-1 Minami-Kogushi, Ube, Yamaguchi 755-8505, Japan

E-mail: hnagano@yamaguchi-u.ac.jp

Abbreviations: CRC, colorectal cancer; CRCwLM, colorectal cancer with liver metastasis; CRCwoLM, colorectal cancer without liver metastasis; miRNA, microRNA; RT-qPCR, reverse transcription-quantitative polymerase chain reaction; FFPE, formalin-fixed paraffin-embedded; SSC, saline-sodium citrate; SDS, sodium dodecyl sulfate; SD, standard deviation; ISH, in situ hybridization; LNA-ISH, locked nucleic acid-in situ hybridization; DIG, digoxigenin-UTP; CAF, cancer associated fibroblast; NF, normal fibroblast

Key words: colorectal cancer, stromal tissue, tumor microenvironment, microRNA, liver metastasis, microarray analysis
miRNA expression and clinicopathological factors was assessed in 101 advanced CRC samples. The localization of candidate miRNAs in CRCs was analyzed using in situ hybridization analysis (ISH). The microarray analysis identified six miRNAs with expression differing between the CRCwLM and CRCwoLM cancer stroma. Validation using RT-qPCR analysis of the stroma showed that the expression levels of miR-221 and miR-222 in the cancer stroma were significantly higher in CRCwLM than in CRCwoLM. The RT-qPCR analysis of 101 CRC samples showed that a high expression level of miR-221 or miR-222 in the cancer stroma was associated with liver metastasis, distant metastasis, and shorter overall survival rate of patients with $\mathrm{CRC}(\mathrm{P}<0.05)$. Increased levels of miR-221 and miR-222 were observed in cancer cells and in fibroblasts in the stromal tissue in the ISH analysis. The results suggested that the overexpression of miR-221 and miR-222 in the cancer stroma is associated with the metastatic activity and malignant potential in patients with CRC.

\section{Introduction}

Colorectal cancer (CRC) is the third most commonly diagnosed cancer in men and the second in women, with $\sim 1.4$ million cases and a mortality rate of 693,900 in 2012 (1). In patients with $\mathrm{CRC}, \sim 25 \%$ present with metastases at the time of diagnosis (2), and $\sim 50 \%$ of patients with CRC develop liver metastases $(3,4)$. Metastatic CRC is associated with a particularly poor prognosis. Despite advances in treatment over previous decades (5), the 5-year-survival rate for patients with metastatic CRC remains $<10 \%$ (6). Extensive investigation of the underlying molecular networks of metastasis is important for the development of effective targeted therapy for patients with metastatic CRC.

Although the overarching focus of cancer research in the last four decades has been on the malignant cancer cell, it has become well established that stromal cells in the tumor 
microenvironment are important in tumor progression $(7,8)$. A variety of stromal cells in the tumor microenvironment are recruited to tumors, and crosstalk between cancer cells and stromal cells is critical for tumor progression and the development of metastases (9). Secreted proteins, including cytokines, chemokines and growth factors, have been considered to occupy the main role in this crosstalk. However, tumor-derived exosomes, which contain various proteins and RNAs, have also been shown to be involved in this crosstalk (10). In tumor microenvironments, extracellular microRNAs (miRNAs), including miRNAs in exosomes, have been suggested to influence tumor progression via bidirectional tumor-to-stromal and stromal-to-tumor communication (11). Therefore, miRNA expression analysis of stromal cells is important for elucidation of the role of miRNAs in cancer progression in the tumor microenvironment. Although there have been a number of reports of comprehensive miRNA expression analysis of stromal cells $(12,13)$, all have involved the analyses of the differences in miRNA expression between cancer stromal cells and normal stromal cells. In order to understand how stromal miRNAs are involved in cancer metastasis, it is necessary to compare the miRNA profile of the cancer stroma in cancer with metastasis to that of the cancer stroma in cancer without metastasis. Comprehensive miRNA expression analysis comparing cancer stroma in cancer with metastasis with that in cancers without metastasis is lacking. The purpose of the present study was to identify the miRNAs whose expression in the CRC stroma is involved in metastatic ability.

\section{Materials and methods}

Patients and tissue samples. The specimens of 113 patients with primary CRC, who had undergone surgical resection in Yamaguchi University Medical Hospital (Yamaguchi, Japan) between January 2008 and December 2013, were used in the present study. All patients had undergone resection of the primary tumor, and among the 31 patients with distant metastases, three patients had undergone hepatectomy. None of the patients had received preoperative treatments, for example, chemotherapy and/or radiation.

For screening in the miRNA array analysis, the frozen specimens of primary CRC from 12 patients were used. For RT-qPCR analysis, the formalin-fixed paraffin embedded tissue (FFPE) specimens of 101 cases of primary CRC were used. Of these 101 CRC FFPE samples, 40 samples (20 CRCwLM and 20 CRCwoLM) were used for reverse transcription-quantitative polymerase chain reaction (RT-qPCR) validation of the array analysis (Fig. 1). Survival analysis was performed for all 101 of the cases from which samples were used for RT-qPCR analysis. All samples were obtained with informed consent from the patients. The study protocol was approved by the Institutional Review Board for the Use of Human Subjects at the Yamaguchi University School of Medicine (H17-83).

Tissue preparation: Laser capture microdissection and RNA extraction. For the miRNA array analysis, frozen cancer tissue sections were immediately cut into 5-mm cubes and embedded in Tissue-Tek OCT compound medium (Sakura Finetech, Co., Ltd., Tokyo, Japan) following resection. The sections then were fixed in liquid nitrogen and stored at $-80^{\circ} \mathrm{C}$. Frozen specimens were cut into $10-\mu \mathrm{m}$-thick slices using a cryostat, and these sections were mounted onto foil-coated glass membrane slides (Leica Microsystems GmbH, Wezlar, Germany). The tissue sections were stained with toluidine blue prior to air drying. The FFPE specimens were cut into $10-\mu \mathrm{m}$-thick sections using a microtome, and these sections were mounted onto foil-coated glass membrane slides. The tissue sections were fixed in $70 \%$ ethanol for $30 \mathrm{sec}$ and stained with hematoxylin and eosin prior to dehydration (5 min each in 70, 95 and $100 \%$ ethanol). The stained frozen or FFPE sections were microdissected using an LMD7000 Laser Microdissection system (Leica Microsystems GmbH). The cancer cells and cancer stromal tissues were visualized under a bright-field microscope (magnification, x100) and selectively separated by activation of the laser. From each slide, $1 \times 10^{7}-2 \times 10^{7} \mu \mathrm{m}^{2}$ epithelial or stromal cells were captured.

RNA extraction and miRNA microarray. Total RNA was extracted from dissected tissue using the miRNeasy FFPE kit (Qiagen GmbH, Hilden, Germany) according to the manufacturer's protocol. The extracted total RNA (250 ng) was labeled with Cy5 using the 3D-Gene miRNA labeling kit (Toray Industries, Inc., Kanagawa, Japan). The labeled RNAs were hybridized onto 3D-Gene Human miRNA Oligo chips containing 2,555 miRNAs (Human_miRNA_Ver20; Toray Industries, Inc.). The annotation and oligonucleotide sequences of the probes conformed to the miRBase miRNA database (http://microrna.sanger.ac.uk/sequences/). Following stringent washes (1st wash: $0.5 \mathrm{X}$ saline-sodium citrate (SSC)/0.1\% sodium dodecyl sulfate (SDS) solution; 2nd wash: $0.2 \mathrm{X}$ SSC/0.1\%SDS solution; 3rd wash: 0.05X SSC solution), fluorescent signals were scanned with the 3D-Gene Scanner (Toray Industries, Inc.) and analyzed using 3D-Gene Extraction software (Ver 2.0.0.7; Toray Industries, Inc.). The raw data of each spot were normalized by substitution with a mean intensity of the background signal determined by all blank spots' signal intensities of $95 \%$ confidence intervals. Measurements of spots with signal intensities differing from the background signal intensity by greater than two standard deviations (SDs) were considered to be valid. The relative expression level of a given miRNA was calculated by comparing the signal intensities of the valid spots throughout the microarray experiments. The normalized data were globally normalized per array, such that the median of the signal intensity was adjusted to 100 .

$R T-q P C R$ analysis. miR-221, miR-222, miR-659, miR-4470, miR-4669, miR-5703 and RNU6B (internal control)-specific cDNA synthesis was performed using $10 \mathrm{ng}$ of total RNA and TaqMan miRNA primers (Applied Biosystems; Thermo Fisher Scientific, Inc., Waltham, MA, USA). RT-qPCR analyses were performed using the following TaqMan miRNA assays: miR-221-3p (ID000524), miR-222-3p (ID002276), miR-659 (ID001514), miR-4470 (ID464583_mat), miR-4669 (ID464125_mat), miR5703 (ID472811_mat) and RNU6B (ID001093) with specific primers (Applied Biosystems; Thermo Fisher Scientific, Inc.) as previously described (14). In brief, cDNA was synthesized from total RNA (10 ng) in a $7.5-\mu 1$ reaction volume (RT primer $1.5 \mu \mathrm{l}$, total RNA lysate $2.5 \mu \mathrm{l}$, RT mix $3.5 \mu \mathrm{l}$ ) using the TaqMan ${ }^{\circledR}$ MicroRNA Reverse Transcription kit. The reactions were performed at $16^{\circ} \mathrm{C}$ for 
Table I. Clinicopathological data for the 12 cases of CRC analyzed in the miRNA microarray.

\begin{tabular}{|c|c|c|c|c|c|c|c|c|c|c|c|c|}
\hline \multirow{2}{*}{$\begin{array}{l}\text { Features } \\
\text { Case }\end{array}$} & \multicolumn{6}{|c|}{ CRC without liver metastasis } & \multicolumn{6}{|c|}{$\mathrm{CRC}$ with liver metastasis } \\
\hline & 1 & 2 & 3 & 4 & 5 & 6 & 7 & 8 & 9 & 10 & 11 & 12 \\
\hline Age (years) & 87 & 69 & 61 & 75 & 83 & 80 & 48 & 65 & 66 & 64 & 53 & 69 \\
\hline Sex & $\mathrm{F}$ & $\mathrm{F}$ & M & $\mathrm{F}$ & $\mathrm{M}$ & M & $\mathrm{F}$ & M & $\mathrm{F}$ & M & M & $\mathrm{F}$ \\
\hline Size $(\mathrm{mm})$ & 90 & 75 & 92 & 70 & 50 & 40 & 30 & 60 & 40 & 120 & 80 & 28 \\
\hline Depth & $\mathrm{T} 3$ & $\mathrm{~T} 3$ & $\mathrm{~T} 4$ & $\mathrm{~T} 4$ & $\mathrm{~T} 2$ & $\mathrm{~T} 4$ & $\mathrm{~T} 3$ & $\mathrm{~T} 3$ & $\mathrm{~T} 3$ & $\mathrm{~T} 3$ & $\mathrm{~T} 4$ & $\mathrm{~T} 4$ \\
\hline Histological type & tu 2 & tu 2 & tu 2 & tu 2 & tu 1 & tu 2 & tu 2 & tu 2 & tu 2 & tu 2 & tu 2 & tu 2 \\
\hline Lymph node metastasis & $(-)$ & $(-)$ & $(-)$ & $(-)$ & $(-)$ & $(-)$ & $(+)$ & $(+)$ & $(+)$ & $(+)$ & $(+)$ & $(-)$ \\
\hline Liver metastasis & $(-)$ & $(-)$ & $(-)$ & $(-)$ & $(-)$ & $(-)$ & $(+)$ & $(+)$ & $(+)$ & $(+)$ & $(+)$ & $(+)$ \\
\hline Stage & IIA & IIA & IIB & IIB & I & IIB & IV & IV & IV & IV & IV & IV \\
\hline
\end{tabular}

F, female; M, male; T3, tumor invades through the muscularis propria into the pericolorectal tissues; T4, tumor invades the visceral peritoneum or invades or adheres to adjacent organ or structure; T2, tumor invades muscularis propria; tu 1, well-differentiated tubular adenocarcinoma; tu 2, moderately differentiated tubular adenocarcinoma.

$30 \mathrm{~min}$ and then at $42^{\circ} \mathrm{C}$ for $30 \mathrm{~min}$, and were inactivated at $85^{\circ} \mathrm{C}$ for $5 \mathrm{~min}$. RT-qPCR analysis was performed using the LightCycler ${ }^{\circledR} 480$ System II (Roche Diagnostics, Tokyo, Japan). The reactions were performed for $10 \mathrm{~min}$ at $95^{\circ} \mathrm{C}$, and then for 55 cycles with denaturation for $15 \mathrm{sec}$ at $95^{\circ} \mathrm{C}$ and annealing/extension for $60 \mathrm{sec}$ at $60^{\circ} \mathrm{C}$. The relative expression of miRNA to RNU6B RNA was calculated using the $2^{-\Delta \Delta \mathrm{Cq}}$ method (15). The CRC samples were categorized into miR-221 and miR-222 weak and strong expression groups according to the expression levels of miR-221 and miR-222 as determined by RT-qPCR analysis, using RNU6B as the control. High expression was defined as an expression level above the median value of the $101 \mathrm{CRC}$ samples for each miRNA.

miRNA in situ hybridization (ISH). Of the 101 CRC FFPE samples, 20 samples, (CRCwLM, n=12; CRCwoLM, n=8) were used for ISH analysis. The locked nucleic acid (LNA)-ISH system was used to investigate the localization of miR-221 and miR-222. LNA-ISH was performed according to the manufacturer's protocol and relevant LNA-ISH literature (16). Briefly, the FFPE advanced colon cancer tissues were cut into $5-\mu$ m-thick sections and deparaffinized. Following treatment with proteinase $\mathrm{K}$ and post-fixation with $4 \%$ paraformaldehyde (Wako Pure Chemical Industries, Osaka, Japan), the slides were hybridized with the 5' (digoxigenin-UTP) DIG-labeled miRCURY LNA ${ }^{\mathrm{TM}}$ detection probe, miR-221, and miR-222 (18115-01 and 38499-01; Qiagen GmbH), for $8 \mathrm{~h}$ at $52^{\circ} \mathrm{C}$ using the Ventana Discovery Ultra instrument (Ventana Medical Systems, Inc. Tucson, AZ, USA). The digoxigenin was detected with a polyclonal anti-DIG antibody and an alkaline phosphatase-conjugated secondary antibody (Ventana Medical Systems, Inc.), using nitro blue tetrazolium and 5-bromo-4-chloro-3-indolyl phosphate as the substrate. The LNA U6 snRNA probe was used as a positive control for every specimen. The 5' DIG-labeled miRCURY LNA ${ }^{\mathrm{TM}}$ detection probe for human mature miR-221-3p (5'-GAAAGCCAG CAGACAATGTAGCT-3'), miR-222-3p (5'-ACCCAGTAG CCAGATGTAGCT-3'), U6-positive control, and scrambled negative control were all purchased from Exiqon A/S (Vedbaek, Denmark). Signals from the tumor cells and stromal cells were classified as negative (-) or positive (+), respectively.

Statistical analysis. All calculations were performed using the SPSS software package version 19.0 (SPSS, Inc., Chicago, IL, USA). Differences between groups were estimated using the Mann-Whitney U test. Categorical variables were compared using Fisher's exact test. Patient outcome survival curves were calculated using the Kaplan-Meier method. Factors shown to be of prognostic significance in univariate models were evaluated in a multivariate Cox proportional hazard model. To validate the association between survival rates and expression of the candidate miRNAs, the following approach was used to divide the patients into two groups according to relative expression levels of candidate miRNAs. For miRNAs, the median values of the expression data were used as the cut-off. Survival was defined as the interval from the date of diagnosis until the date of CRC-associated mortality, date of mortality from other cause, or the end of follow-up (June 30, 2017), whichever came first. Patients lost to follow-up were censored at the date of the final follow-up contact. All statistical analyses assumed a two-sided alternative with a $5 \%$ level of significance.

\section{Results}

miRNA array analysis of primary CRCwLM or CRCwoLM. An overview of the experimental design and selection of candidate miRNAs is shown in Fig. 1. To investigate the miRNAs associated with liver metastasis in cancer stromal tissue, array-based miRNA profiling was performed. The stromal tissue of six cases of primary CRCwoLM and that of six cases of primary CRCwLM were profiled on the Toray 3D-Gene Human miRNA Oligo chips ver. 19. The clinicopathological data of the patients are summarized in Table I. miRNAs with intensity levels higher than the negative control +2 SD were selected in all cases. This filtering resulted in the identification of 1,024 miRNAs among a total of 2,555. The Fischer ratio 


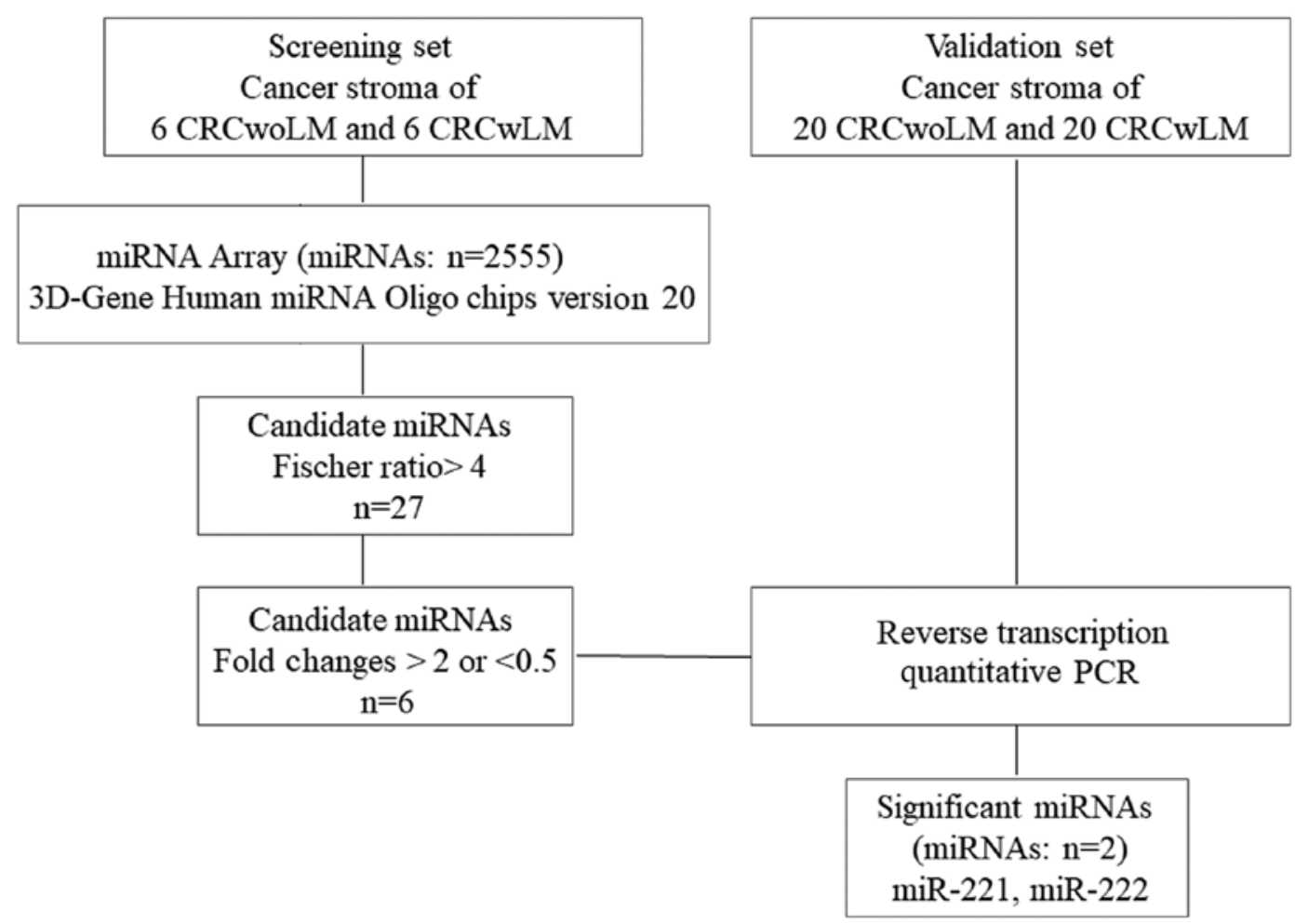

Figure 1. Flow chart of identification of miR-221 and miR-222 as candidate miRNAs. 3D-Gene Human miRNA Oligo chips were used for screening candidate miRNAs, and RT-qPCR analysis was used for validation. Samples from six cases of CRCwoLM and six cases of CRCwLM were used for screening, and $20 \mathrm{CRC}$ woLM samples and $20 \mathrm{CRCwLM}$ samples were used for RT-qPCR validation of the array analysis. Patients in the screening set and validation set were independent groups; samples in the screening set were frozen sections and validation samples were formalin-fixed paraffin-embedded. miRNA/miR, microRNA; CRC, colorectal cancer; CRCwLM, CRC with liver metastasis; CRCwoLM, CRC without liver metastasis; RT-qPCR, reverse transcription-quantitative polymerase chain reaction.

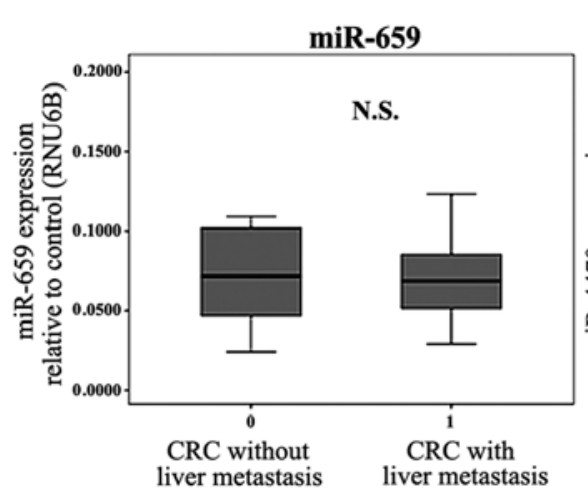

miR-5703

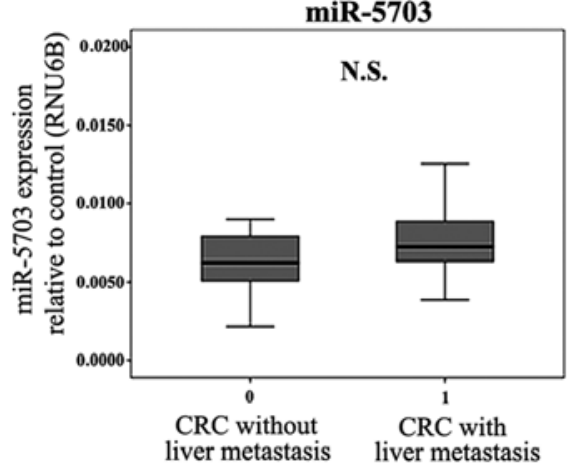

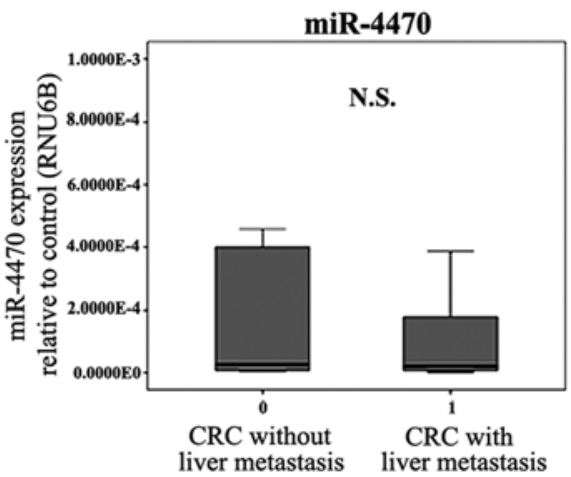

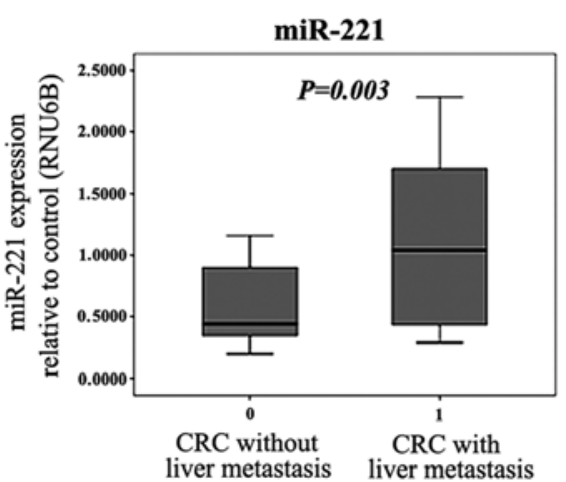

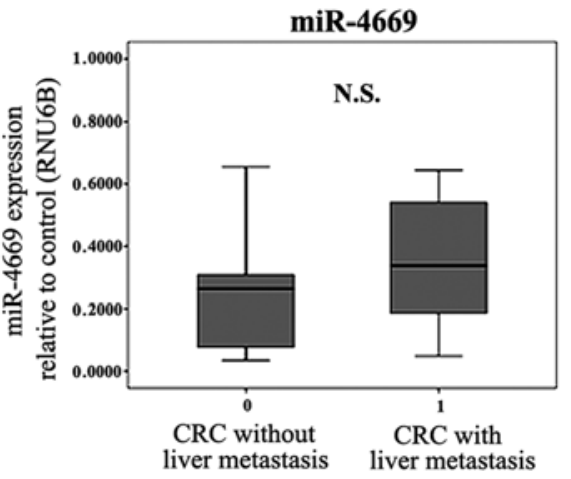

miR-222

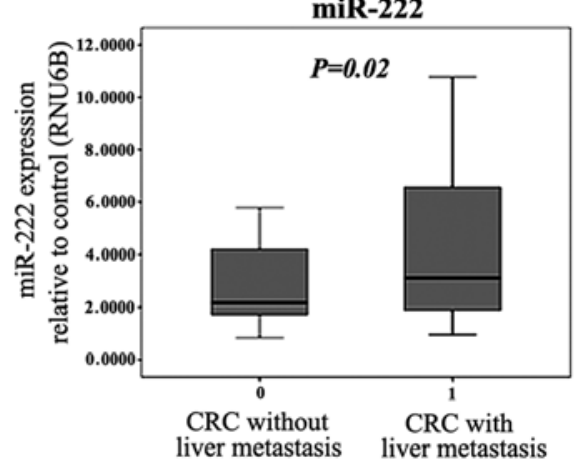

Figure 2. Validation RT-qPCR of the six miRNAs identified in the comprehensive array screen. Box and whisker plots of RT-qPCR analysis of the expression level in the cancer stroma of CRC with or without liver metastasis $(n=20$ each) of the four downregulated miRNAs (miR-659, $-4470,-4669$ and -5703$)$ and the two upregulated miRNAs (miR-221 and miR-222) in CRC with liver metastasis, compared with CRC without liver metastasis in the microarray screen. The line within the box indicates the median value, which was used as the cut-off for high or low miRNA expression. miRNA/miR, microRNA; N.S., not significant; CRC, colorectal cancer; RT-qPCR, reverse transcription-quantitative polymerase chain reaction. 
Table II. Dysregulated miRNAs in cancer stromal tissue on comparison of colorectal cancer with and without liver metastasis.

\begin{tabular}{|c|c|c|c|c|c|}
\hline miRNA & $\begin{array}{l}\text { Signal intensity in cancer } \\
\text { stroma without liver metastasis }\end{array}$ & $\begin{array}{c}\text { Signal intensity in cancer stroma } \\
\text { with liver metastasis }\end{array}$ & $\begin{array}{l}\text { Fold } \\
\text { change }\end{array}$ & Regulation & $\begin{array}{l}\text { Fischer } \\
\text { ratio }\end{array}$ \\
\hline hsa-miR-4698 & 84.3853 & 59.9454 & 0.7104 & Down & 8.6870 \\
\hline hsa-miR-6862-5p & 43.2356 & 23.2163 & 0.5370 & Down & 7.7798 \\
\hline hsa-miR-491-5p & 621.6555 & 358.3432 & 0.5764 & Down & 7.2940 \\
\hline hsa-miR-7855-5p & 45.1489 & 23.2163 & 0.5142 & Down & 6.5106 \\
\hline hsa-miR-602 & 79.6585 & 43.7653 & 0.5494 & Down & 6.0467 \\
\hline hsa-miR-4726-5p & 282.4948 & 203.2291 & 0.7194 & Down & 5.9314 \\
\hline hsa-miR-6845-5p & 690.9057 & 480.6378 & 0.6957 & Down & 5.6611 \\
\hline hsa-miR-371b-5p & 141.0927 & 84.1496 & 0.5964 & Down & 5.6109 \\
\hline hsa-miR-6790-3p & 209.2740 & 140.5168 & 0.6714 & Down & 5.3770 \\
\hline hsa-miR-4533 & 59.9515 & 32.3644 & 0.5398 & Down & 5.2842 \\
\hline hsa-miR-663a & $3,729.6112$ & $2,507.9348$ & 0.6724 & Down & 5.2337 \\
\hline hsa-miR-1237-5p & $9,092.0858$ & $6,981.4697$ & 0.7679 & Down & 5.0164 \\
\hline hsa-miR-6742-5p & 91.7006 & 53.0911 & 0.5790 & Down & 5.0012 \\
\hline hsa-miR-4470 & 71.7076 & 33.4636 & 0.4667 & Down & 4.9666 \\
\hline hsa-miR-4750-3p & 182.9980 & 149.9362 & 0.8193 & Down & 4.9492 \\
\hline hsa-miR-665 & 622.2152 & 380.7198 & 0.6119 & Down & 4.9448 \\
\hline hsa-miR-221-3p & 172.4139 & 384.7967 & 2.2318 & Up & 4.8359 \\
\hline hsa-miR-1238-5p & 326.3151 & 238.1282 & 0.7297 & Down & 4.7928 \\
\hline hsa-miR-659-3p & 109.3211 & 51.4299 & 0.4704 & Down & 4.7122 \\
\hline hsa-miR-4669 & 123.4231 & 58.7635 & 0.4761 & Down & 4.5689 \\
\hline hsa-miR-4513 & 333.8607 & 248.4870 & 0.7443 & Down & 4.5341 \\
\hline hsa-miR-3180-3p & 657.2006 & 471.0584 & 0.7168 & Down & 4.5194 \\
\hline hsa-miR-3185 & 444.7393 & 294.6611 & 0.6625 & Down & 4.5179 \\
\hline hsa-miR-222-3p & 86.9045 & 193.2362 & 2.2235 & Up & 4.4753 \\
\hline hsa-miR-4257 & $1,156.5877$ & $1,437.9049$ & 1.2432 & Up & 4.3621 \\
\hline hsa-miR-5196-5p & 154.3040 & 111.5328 & 0.7228 & Down & 4.3175 \\
\hline hsa-miR-5703 & 68.1390 & 33.4572 & 0.4910 & Down & 4.2515 \\
\hline
\end{tabular}

miR, microRNA.

was used to evaluate the potential of the selected miRNAs to discriminate between CRCwLM and CRCwoLM (17). The 1,024 miRNAs were ranked in order of decreasing Fischer ratio. The 27 miRNAs that were significantly dysregulated in cancer stromal tissues, comparing between CRCwoLM and CRCwLM, are listed in Table II (Fischer ratio $>4$ ). For the selection of candidate miRNAs among these 27 miRNAs, to permit comparison between CRCwLM and CRCwoLM, a fold change of 2.0 or 0.5 was used as the cut-off. Using this cut-off led to the identification of four miRNAs (miR-659, -4470, -4669 and -5703 ) that were downregulated and two miRNAs (miR-221 and miR-222) that were upregulated in CRCwLM compared with CRCwoLM.

Validation of the miRNA array profiling by RT-qPCR analysis. To confirm the microarray findings, RT-qPCR analysis was used to measure the expression level of these six miRNAs, described as above, in the stromal tissues of 20 cases CRCwLM and 20 cases of CRCwoLM. The expression levels of miR-221 and miR-222 in the cancer stromal tissues were significantly higher in CRCwLM than in CRCwoLM $(\mathrm{P}=0.003$ and $\mathrm{P}=0.02$, respectively), whereas no significant difference was found in the expression of the four downregulated miRNAs (miR-659, -4470, -4669 and -5703) between CRCwLM and CRCwoLM (Fig. 2).

Association of the expression ofmiR-221 andmiR-222 in cancer stromal tissues with clinicopathological factors. To evaluate whether the expression of miR-221 or miR-222 was associated with clinicopathological factors and prognosis, RT-qPCR analysis was used to analyze the expression of miR-221 and miR-222 in 101 CRC FFPE sample sets of cancer stromal tissues and corresponding cancer cells; RNU6B was used as the control. The clinicopathological analysis showed that the group with a high expression of miR-221 in cancer stromal tissues, that is, cases with specimens in which the expression of miR-221 was above the median value, had more advanced venous invasion $(\mathrm{P}=0.023)$, liver metastasis $(\mathrm{P}=0.028)$, and distant metastasis $(\mathrm{P}=0.003)$ than the low-expression group (Table III). The group with a high expression of 
Table III. Expression of miR-221 in the cancer stroma and its association with clinicopathological factors.

\begin{tabular}{|c|c|c|c|c|c|c|}
\hline \multirow[b]{2}{*}{ Clinicopathological factor } & \multicolumn{2}{|c|}{ miR221 expression in stroma } & \multirow[b]{2}{*}{ P-value } & \multicolumn{2}{|c|}{ miR221 expression in cancer cells } & \multirow[b]{2}{*}{ P-value } \\
\hline & $\operatorname{High}(\mathrm{n}=50)$ & Low $(\mathrm{n}=51)$ & & $\operatorname{High}(\mathrm{n}=50)$ & Low $(\mathrm{n}=51)$ & \\
\hline Age (years) & $68.3 \pm 11.7$ & $67.8 \pm 11.6$ & $\mathrm{P}=0.851$ & $67.4 \pm 12.2$ & $69.0 \pm 11.0$ & $\mathrm{P}=0.394$ \\
\hline Sex & & & $\mathrm{P}=0.356$ & & & $P=0.767$ \\
\hline Male & 23 & 26 & & 25 & 27 & \\
\hline Female & 27 & 25 & & 25 & 24 & \\
\hline Degree of differentiation & & & $\mathrm{P}=0.358$ & & & $\mathrm{P}=0.383$ \\
\hline Well/moderate & 44 & 47 & & 46 & 45 & \\
\hline Poor & 6 & 4 & & 4 & 6 & \\
\hline Tumor size (mm) & & & $\mathrm{P}=0.187$ & & & $\mathrm{P}=0.378$ \\
\hline$<50$ & 25 & 31 & & 29 & 27 & \\
\hline$\geq 50$ & 25 & 20 & & 21 & 24 & \\
\hline Depth & & & $\mathrm{P}=0.098$ & & & $\mathrm{P}=0.098$ \\
\hline $\mathrm{T} 2 / \mathrm{T} 3$ & 25 & 33 & & 25 & 33 & \\
\hline $\mathrm{T} 4$ & 25 & 18 & & 25 & 18 & \\
\hline Lymph node metastasis & & & $\mathrm{P}=0.227$ & & & $\mathrm{P}=0.227$ \\
\hline Absent & 16 & 21 & & 16 & 21 & \\
\hline Present & 34 & 30 & & 34 & 30 & \\
\hline Lymphatic invasion & & & $P=0.346$ & & & $\mathrm{P}=0.369$ \\
\hline Absent & 5 & 3 & & 3 & 5 & \\
\hline Present & 45 & 48 & & 47 & 46 & \\
\hline Venous invasion & & & $\mathrm{P}=0.023$ & & & $\mathrm{P}=0.062$ \\
\hline Absent & 8 & 18 & & 9 & 17 & \\
\hline Present & 42 & 33 & & 41 & 34 & \\
\hline Liver metastasis & & & $\mathrm{P}=0.028$ & & & $\mathrm{P}=0.164$ \\
\hline Absent & 33 & 43 & & 35 & 41 & \\
\hline Present & 17 & 8 & & 15 & 10 & \\
\hline Distant metastasis & & & $\mathrm{P}=0.003$ & & & $\mathrm{P}=0.083$ \\
\hline Absent & 29 & 43 & & 32 & 40 & \\
\hline Present & 21 & 8 & & 18 & 11 & \\
\hline Stage & & & $\mathrm{P}=0.163$ & & & $\mathrm{P}=0.288$ \\
\hline $\mathrm{I} / \mathrm{II}$ & 14 & 20 & & 15 & 19 & \\
\hline III/IV & 36 & 31 & & 35 & 32 & \\
\hline Recurrence within 3 years & High $(n=30)$ & Low $(n=42)$ & $\mathrm{P}=0.087$ & High $(n=33)$ & Low $(n=39)$ & $\mathrm{P}=0.563$ \\
\hline Absent & 20 & 35 & & 25 & 30 & \\
\hline Present & 10 & 7 & & 8 & 9 & \\
\hline
\end{tabular}

T2, tumor invades muscularis propria; T3, tumor invades through the muscularis propria into the pericolorectal tissues; T4, tumor invades the visceral peritoneum or invades or adheres to adjacent organ or structure; miR, microRNA.

miR-222 in cancer stromal tissues had more advanced depth of tumor invasion $(\mathrm{P}=0.045)$, liver metastasis $(\mathrm{P}=0.009)$, and distant metastasis $(\mathrm{P}=0.003)$ than the low-expression group (Table IV). By contrast, unlike in the stromal tissue, the clinicopathological factors and the expression of miR-221 and miR-222 in cancer cells only showed a tendency to be associated with distant metastasis (Tables III and IV).

Association of the expression of miR-221 and miR-222 and survival rates. The overall survival rate of the patients according to the miR-221 and miR-222 expression status of the cancer stroma are shown in Fig. 3A and B. The survival analysis showed that the group with a high expression of miR-221 in cancer stromal tissues had significantly shorter overall survival rates than the group with a low expression $(\mathrm{P}=0.039)$. Similarly, the group with a high expression of miR-222 in cancer stromal tissues had significantly shorter overall survival rate than the group with a low expression $(\mathrm{P}=0.02)$. However, there was no association between the overall survival rate and the expression level of miR-221 or miR-222 in cancer cells (Fig. 3C and D). 
Table IV. Expression level of miR-222 in the cancer stroma and its association with clinicopathological factors.

\begin{tabular}{|c|c|c|c|c|c|c|}
\hline \multirow[b]{2}{*}{ Clinicopathological factor } & \multicolumn{2}{|c|}{ miR222 expression in stroma } & \multirow[b]{2}{*}{ P-value } & \multicolumn{2}{|c|}{ miR222 expression in cancer cells } & \multirow[b]{2}{*}{ P-value } \\
\hline & High $(n=50)$ & Low $(n=51)$ & & High $(n=50)$ & Low $(n=51)$ & \\
\hline Age (years) & $68.7 \pm 11.0$ & $67.4 \pm 12.2$ & $P=0.562$ & $68.8 \pm 10.4$ & $67.3 \pm 12.7$ & $\mathrm{P}=0.494$ \\
\hline Sex & & & $\mathrm{P}=0.617$ & & & $\mathrm{P}=0.207$ \\
\hline Male & 18 & 31 & & 22 & 27 & \\
\hline Female & 32 & 20 & & 28 & 24 & \\
\hline Degree of differentiation & & & $\mathrm{P}=0.383$ & & & $\mathrm{P}=0.358$ \\
\hline Well/moderate & 46 & 45 & & 44 & 47 & \\
\hline Poor & 4 & 6 & & 6 & 4 & \\
\hline Tumor size (mm) & & & $\mathrm{P}=0.073$ & & & $\mathrm{P}=0.312$ \\
\hline$<50$ & 23 & 33 & & 26 & 30 & \\
\hline$\geq 50$ & 27 & 18 & & 24 & 21 & \\
\hline Depth & & & $\mathrm{P}=0.045$ & & & $P=0.187$ \\
\hline $\mathrm{T} 2 / \mathrm{T} 3$ & 24 & 34 & & 26 & 32 & \\
\hline $\mathrm{T} 4$ & 26 & 17 & & 24 & 19 & \\
\hline Lymph node metastasis & & & $\mathrm{P}=0.184$ & & & $P=0.227$ \\
\hline Absent & 21 & 16 & & 16 & 21 & \\
\hline Present & 29 & 35 & & 34 & 30 & \\
\hline Lymphatic invasion & & & $P=0.141$ & & & $\mathrm{P}=0.631$ \\
\hline Absent & 2 & 6 & & 4 & 4 & \\
\hline Present & 48 & 45 & & 46 & 47 & \\
\hline Venous invasion & & & $\mathrm{P}=0.267$ & & & $\mathrm{P}=0.433$ \\
\hline Absent & 15 & 11 & & 12 & 14 & \\
\hline Present & 36 & 39 & & 38 & 37 & \\
\hline Liver metastasis & & & $\mathrm{P}=0.009$ & & & $P=0.164$ \\
\hline Absent & 32 & 44 & & 35 & 41 & \\
\hline Present & 18 & 7 & & 15 & 10 & \\
\hline Distant metastasis & & & $\mathrm{P}=0.003$ & & & $\mathrm{P}=0.083$ \\
\hline Absent & 29 & 43 & & 32 & 40 & \\
\hline Present & 21 & 8 & & 18 & 11 & \\
\hline Stage & & & $\mathrm{P}=0.241$ & & & $\mathrm{P}=0.288$ \\
\hline $\mathrm{I} / \mathrm{II}$ & 19 & 15 & & 15 & 19 & \\
\hline III/IV & 31 & 36 & & 35 & 32 & \\
\hline Recurrence within 3 years & High $(n=30)$ & Low $(n=42)$ & $P=0.404$ & High $(n=33)$ & Low $(n=39)$ & $\mathrm{P}=0.237$ \\
\hline Absent & 22 & 33 & & 27 & 28 & \\
\hline Present & 8 & 9 & & 6 & 11 & \\
\hline
\end{tabular}

T2, tumor invades muscularis propria; T3, tumor invades through the muscularis propria into the pericolorectal tissues; T4, tumor invades the visceral peritoneum or invades or adheres to adjacent organ or structure; miR, microRNA.

In addition, a Cox proportional hazard regression model was used to determine whether the expression of miR-221 and miR-222 in the cancer stroma was an independent risk factor for overall survival rate (Table $\mathrm{V}$ ). The univariate analysis revealed that high levels of stromal miR-221 ( $\mathrm{P}=0.038)$, high levels of stromal miR-222 ( $\mathrm{P}=0.024)$, higher pathological $\mathrm{T}$ stage $(\mathrm{T} 4 ; \mathrm{P}=0.001)$, and lymph node metastasis $(\mathrm{P}=0.007)$ were significantly associated with poor overall survival rate. The subsequent multivariate analysis confirmed these results and showed that the stromal expression of miR-222 [hazard ratio $(\mathrm{HR})=2.280,95 \%$ confidence interval $(\mathrm{CI})=1.097-4.742$, $\mathrm{P}=0.027)$, higher pathological $\mathrm{T}$ stage $(\mathrm{T} 4 ; \mathrm{HR}=2.078,95 \% \mathrm{CI}$, 1.043-4.142, $\mathrm{P}=0.038)$, and lymph node metastasis $(\mathrm{HR}=3.679$, 95\% CI, 1.497-9.043, $\mathrm{P}=0.005)$ were independent markers for poor overall survival rates in patients with CRC (Table V).

Localization of miR-221 and miR-222 in colon cancer. To investigate the localization of miR-221 and miR-222 in cancer tissue, ISH was performed. The negative control groups are shown in Fig. 4A and B. In CRC with liver metastasis, miR-221 

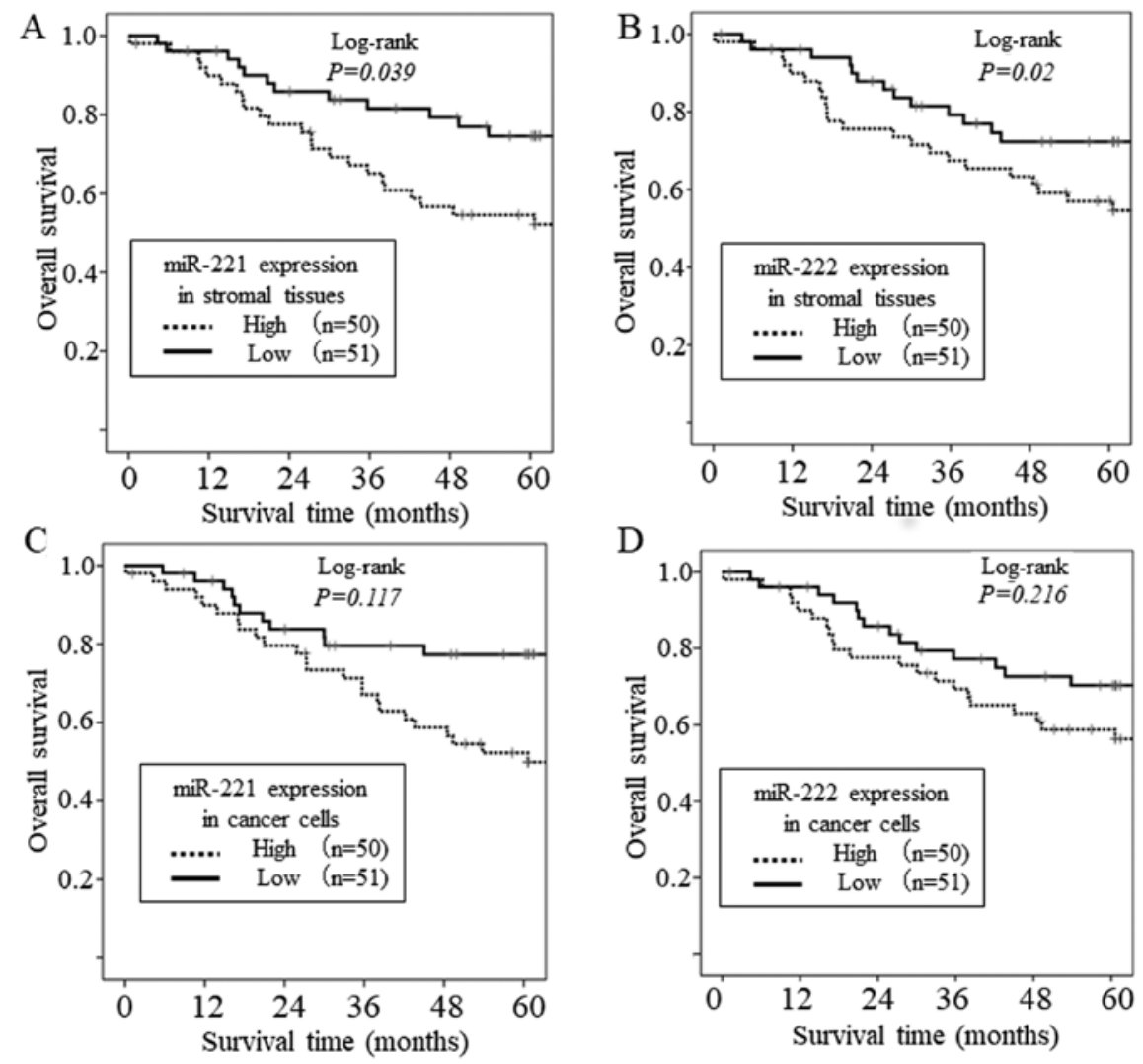

Figure 3. Kaplan-Meier analyses of overall survival according to the expression level of miR-221 and miR-222 in advanced colorectal cancer. Overall survival of groups is shown for cases with high or low expression of (A) miR-221 in cancer stromal tissues; (B) miR-222 in cancer stromal tissues; (C) miR-221 in cancer cells; and (D) miR-222 in cancer cells. miR, microRNA.

Table V. Univariate and multivariate Cox proportional hazard models of overall survival rates.

\begin{tabular}{|c|c|c|c|c|c|c|}
\hline \multirow[b]{2}{*}{ Variable } & \multicolumn{3}{|c|}{ Univariate analysis } & \multicolumn{3}{|c|}{ Multivariate analysis } \\
\hline & HR & P-value & $95 \% \mathrm{CI}$ & HR & P-value & $95 \% \mathrm{CI}$ \\
\hline \multicolumn{7}{|l|}{ miR-221 (stroma) } \\
\hline \multicolumn{7}{|l|}{ miR-222 (stroma) } \\
\hline $\begin{array}{l}\text { Low, vs. high } \\
\text { miR-221 (cancer cell }\end{array}$ & 2.222 & $\mathrm{P}=0.024$ & $1.110-4.444$ & 2.280 & $\mathrm{P}=0.027$ & $1.097-4.742$ \\
\hline \multicolumn{6}{|l|}{ miR-222 (cancer cell) } & \\
\hline Low, vs. high & 1.506 & $\mathrm{P}=0.22$ & $0.780-2.938$ & & & \\
\hline $\begin{array}{l}\text { Age (years) } \\
<60, \text { vs. } \geq 60\end{array}$ & 1.406 & $\mathrm{P}=0.395$ & $0.641-3.086$ & & & \\
\hline \multicolumn{7}{|l|}{ Sex } \\
\hline Male, vs. female & 1.644 & $\mathrm{P}=0.142$ & $0.847-3.192$ & & & \\
\hline $\begin{array}{l}\text { Tumor size (mm) } \\
<50, \text { vs. } \geq 50\end{array}$ & 1.036 & $\mathrm{P}=0.916$ & $0.537-1.999$ & & & \\
\hline \multicolumn{7}{|l|}{ Depth } \\
\hline T2/T3, vs. T4 & 2.977 & $\mathrm{P}=0.001$ & $1.543-5.746$ & 2.078 & $\mathrm{P}=0.038$ & $1.043-4.142$ \\
\hline \multicolumn{7}{|c|}{ Lymph node metastasis } \\
\hline Absent, vs. present & 3.369 & $\mathrm{P}=0.007$ & $1.400-8.106$ & 3.679 & $\mathrm{P}=0.005$ & $1.497-9.043$ \\
\hline
\end{tabular}

HR, hazard ratio; CI, confidence interval; T2, tumor invades muscularis propria; T3, tumor invades through the muscularis propria into the pericolorectal tissues; T4, tumor invades the visceral peritoneum or invades or adheres to adjacent organ or structure; miR, microRNA. 


\section{CRC with liver metastasis}
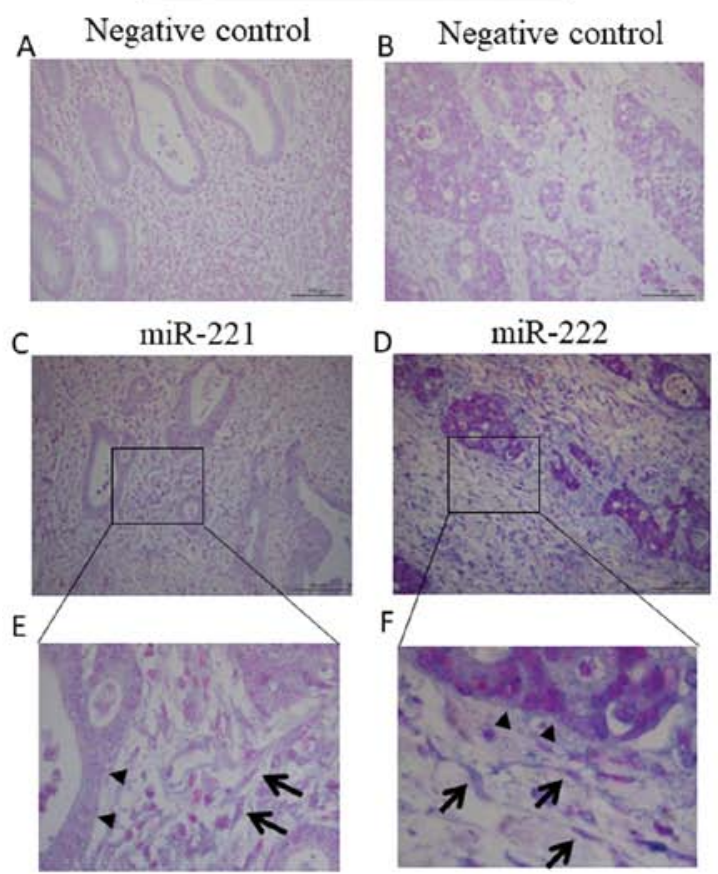

$\underline{\mathrm{CRC}}$ without liver metastasis

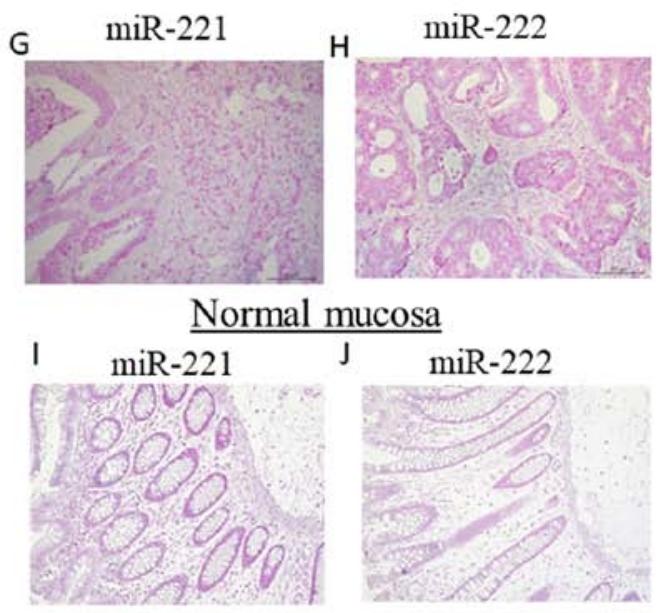

Figure 4. Locked nucleic acid-in situ hybridization detection of miR-221 and miR-222 in primary CRC with or without liver metastasis. Primary CRC with liver metastasis, without liver metastasis, and normal mucosa were analyzed. Positive staining is blue-violet in color. (A) Negative control for miR-221; (B) negative control for miR-222. (C) miR-221 and (D) miR-222 were expressed at high levels in cancer cells and stromal cells in CRC with liver metastasis (magnification, x200). At x400 magnification (E) miR-221 and $(F)$ miR-222, black arrowheads indicate positive expression in cancer cells and black arrows indicate positive expression in fibroblast-like cells Expression levels of (G) miR-221 and (H) miR-222 were low in cancer cells and stromal cells in primary CRC without liver metastasis. (I) miR-221 in normal mucosa; (J) miR-222 in normal mucosa. CRC, colorectal cancer; miR, microRNA.

and miR-222 were localized in the cytoplasm of fibroblasts in stromal tissue and cancer cells (Fig. 4C-F). By contrast, in primary CRC without liver metastasis, there was low expression of miR-221 and miR-222 in cancer cells and stromal cells (Fig. 4G and H). In terms of fibroblasts. 9/12 (75\%) CRCwLM and 2/8 (25\%) CRCwoLM cases $(\mathrm{P}=0.04)$ had miR-222-positive fibroblasts. By contrast, 7/12 (58\%) CRCwLM and 3/8 (37.5\%) CRCwoLM cases $(\mathrm{P}=0.36)$ had
miR-221-positive fibroblasts. The miR-221 or miR-222 signal was observed in $<10 \%$ of non-cancerous tissues (Fig. $4 \mathrm{I}$ and $\mathrm{J}$ ).

\section{Discussion}

The dysregulation of miRNA expression is frequently detected in CRC and has been associated with increased metastatic potential and poor clinical outcome, suggesting the importance of miRNAs in cancer progression $(18,19)$.

In the present study, it was shown that the overexpression of miR-221 and miR-222 in the cancer stromal tissue of primary tumors was associated with malignant potential in patients with CRC. To date, several studies have profiled the expression of miRNAs involved in cancer metastasis in $\mathrm{CRC}$, however, those studies were performed primarily on cancer cells or cancer tissue $(20,21)$. In the present study, the stromal miRNA expression profile of CRCwLM was compared with that of CRCwoLM using microdissection. Using miRNA array analysis, six miRNAs were identified that were differentially expressed between the two patient groups. Following reassessment of these six miRNAs using RT-qPCR analysis, differential expression between CRCwLM and CRCwoLM was confirmed for miR-221 and miR-222. To the best of our knowledge, this is the first comprehensive miRNA array analysis performed to identify miRNAs in the CRC stroma whose expression is associated with metastatic ability. A small number of previous studies have reported differential miRNA expression profiles between the cancer stroma and normal stroma. Nishida et al reported oncogenic miRNAs, including miR-21, miR-221, the miR-17-92a cluster, and the miR-106b-25 cluster, which were upregulated in the cancer stroma compared with the normal stroma. In addition, the upregulation of miR-25 and miR-92a in stromal tissues has been associated with a variety of clinicopathological factors (12). Bullock et al observed distinct patterns of stromal miRNA expression in CRC and paired normal colonic tissue, and reported that stromal levels of miR-21 and miR-556 predicted short disease-free survival and overall survival rates in stage II disease (13). Furthermore, Bullock et al reported the stromal upregulation of miR-214 and downregulation of miR-192, mir-194, miR-200a, and miR-215 in Dukes C CRC compared with Dukes A CRC among 95 miRNAs analyzed using RT-qPCR analysis. However, the results from this particular study were limited as the study only compared five Dukes C samples with five Dukes A samples using RT-qPCR analysis. This low number of samples analyzed may have been insufficient to detect novel stromal miRNAs that are associated with the malignant potential of CRC.

miR-221 and miR-222 are homologous miRNAs, which are encoded on the $\mathrm{X}$ chromosome as part of a locus designated the miR-221-222 cluster (22). This cluster has been found to be overexpressed in various types of human cancer, including CRC (23). In previous years, there have been reports on the association between the metastatic potential of CRC and the expression of miR-221 or mir-222. However, previous studies have analyzed the expression of miR-221 or mir-222 in cancer cells or cancer tissues, or in the blood. To the best of our knowledge, previous studies have not reported that the expression of miR-221 or mir-222 in the cancer stroma was associated with the development 
of CRC. It has been shown that miR-221 and miR-222 promote oncogenesis by downregulating the expression of tumor suppressors, including phosphatase and tensin homolog, reversion-inducing-cysteine-rich protein with kazal motifs, p53 upregulated modulator of apoptosis, and p27 (24-28). Qin and Lui reported that the overexpression of miR-221 enhances CRC cell migration and invasion in vitro and metastasis in vivo (26). Furthermore, miR-221 and miR-222 have the same seed sequence. The fact that two oncogenic miRNAs with the same seed sequence were identified in a comprehensive analysis is of interest, as these miRNAs share the same targets and may work coordinately.

To evaluate the clinicopathologic relevance of the identified miRNAs, the present study analyzed the expression of miR-221and miR-222 in 101 advanced CRC samples. A high expression level of miR-221 or miR-222 in patients with CRC was significantly associated with liver metastasis, distant metastasis, and shorter overall survival rate. Furthermore, it was found that the association between the malignant potential of CRC and the level of miR-221 or miR-222 in the cancer stroma was more marked than that in the cancer cells. Using ISH for miRNA measurement, Uozaki et al reported that the level of miR-21 in cancer cells was not associated with clinicopathological factors, however, the stromal level of miR-21 was associated with several factors in gastric cancer, including tumor stage, size, and nodal metastasis (29). These results are similar to the results of the present study, and the combination of these results suggests that the overexpression of certain oncogenic miRNAs, including miR-21, miR-221 and miR-222, in the cancer stroma may be important for cancer development.

To detect the localization of miR-221 and miR-222 in CRC, ISH was performed in $20 \mathrm{CRC}$ samples. In this analysis, miR-221 and miR-222 were upregulated in the cancer cells and stromal cells, particularly in fibroblasts, in metastatic CRC. Furthermore, the expression of miR-221 and miR-222 in fibroblasts tended to be higher in fibroblasts surrounding cancer cells strongly positive for miR-221 and miR-222. A report by Kosaka et al suggested that, in tumor microenvironments, extracellular miRNAs may influence tumor progression via bidirectional tumor-to-stroma and stroma-to-tumor communication (11). These results suggest that the crosstalk of miR-221 and miR-222 between cancer cells and stromal cells occurs in the cancer microenvironment. The precise mechanisms underlying the upregulation of miR-221 and miR-222 in stromal cells with metastatic CRC remain to be elucidated. One possible mechanism is that the crosstalk of miR-221 and miR-222 between cancer cells and stromal cells is involved in cancer progression. A previous comprehensive array analysis showed that miR-221 is upregulated in cancer-associated fibroblasts (CAFs) compared with that in normal fibroblasts (NFs) in breast cancer (30). Furthermore, Shimoda et al reported that the knockdown of issue inhibitor of metalloproteinase (TIMP) family genes resulted in acquisition of the properties of CAFs by NFs (31). TIMP2 and TIMP3, which belong to the TIMP family, have been reported as being target genes of miR-221 and miR-222 $(32,33)$. These results indicate that miR-221 and miR-222 from tumor-derived exosomes mad modify the cellular phenotype of fibroblasts to that of CAFs.
This change in phenotype can promote the invasion and metastatic potential of the tumor cells.

A limitation of the present study is that no in vivo transfection was performed, therefore, it was not possible to assess whether overexpression of miR-221 or miR-222 in the cancer stroma facilitates metastasis in vivo. In order to confirm this detailed mechanism, it is necessary to transfect miR-221 and/or miR-222 into the cancer stroma rather than into cancer cells. However, it is difficult to selectively transfect the cancer stroma only with specific miRNAs, therefore, no such experiments were performed in the present study. Further functional studies are required in order to clarify the role of stromal miR-221/222 expression.

\section{Acknowledgements}

The authors would like to thank Mr. Yasutake Yano and Mr. Naoya Touyama from the Yamaguchi University School of Medicine for their technical support.

\section{Funding}

The present study was performed as a research program of the Project for Development of Innovative Research on Cancer Therapeutics (P-DIRECT; grant no. 11039020). This study was funded by the Japan Agency for Medical Research and Development (AMED; grant no. 15cm0106085h0005), and was supported in part by a grant for Leading Advanced Projects for Medical Innovation (LEAP; grant no. 16am0001006h0003) from AMED.

\section{Availability of data and materials}

All data generated or analyzed during the present study are included within.

\section{Authors' contributions}

MI, SH, and HN designed the study; MI, HTakenouchi, SK, YuT, STo, YoT and SYo collected the data; MI, SH, RT, HTanaka, HTakenouchi, KF, and MK performed the experiments. MI, SH, KS, NS, STa, TU, and SYa performed the statistical analysis; MI, SH, and HN wrote the manuscript. All authors read and approved the final manuscript and agree to be accountable for all aspects of the research in ensuring that the accuracy or integrity of any part of the work are appropriately investigated and resolved.

\section{Ethics approval and consent to participate}

Written informed consent was obtained from each patient at the time of enrollment. The study was performed in accordance with the Declaration of Helsinki on experiments involving human subjects. The study protocol was approved by the Institutional Ethics Review Boards of Yamaguchi University.

\section{Patient consent for publication}

Written informed consent was obtained from all patients. 


\section{Competing interests}

The authors state that they have no competing interests.

\section{References}

1. Torre LA, Bray F, Siegel RL, Ferlay J, Lortet-Tieulent J and Jemal A: Global cancer statistics, 2012. CA Cancer J Clin 65 87-108, 2015.

2. Siegel R, Desantis C and Jemal A: Colorectal cancer statistics, 2014. CA Cancer J Clin 64: 104-117, 2014.

3. Rees M, Tekkis PP, Welsh FK, O'Rourke T and John TG: Evaluation of long-term survival after hepatic resection for metastatic colorectal cancer: A multifactorial model of 929 patients. Ann Surg 247: 125-135, 2008.

4. Leporrier J, Maurel J, Chiche L, Bara S, Segol P and Launoy G: A population-based study of the incidence, management and prognosis of hepatic metastases from colorectal cancer. Br J Surg 93: 465-474, 2006

5. Colvin H, Mizushima T, Eguchi H, Takiguchi S, Doki Y and Mori M: Gastroenterological surgery in Japan: The past, the present and the future. Ann Gastroenterol Surg 1: 5-10, 2017.

6. Giessen C, Laubender RP, Ankerst DP, Stintzing S, Modest DP, Mansmann U and Heinemann V: Progression-free survival as a surrogate endpoint for median overall survival in metastatic colorectal cancer: Literature-based analysis from 50 randomized first-line trials. Clin Cancer Res 19: 225-235, 2013.

7. Penfornis $\mathrm{P}$, Vallabhaneni KC, Whitt $\mathbf{J}$ and Pochampally $\mathrm{R}$ : Extracellular vesicles as carriers of microRNA, proteins and lipids in tumor microenvironment. Int J Cancer 138: 14-21, 2016.

8. Hanahan D and Coussens LM: Accessories to the crime: Functions of cells recruited to the tumor microenvironment. Cancer Cell 21: 309-322, 2012.

9. Joyce JA and Pollard JW: Microenvironmental regulation of metastasis. Nat Rev Cancer 9: 239-252, 2009.

10. Valadi H, Ekstrom K, Bossios A, Sjostrand M, Lee JJ and Lotvall JO: Exosome-mediated transfer of mRNAs and microRNAs is a novel mechanism of genetic exchange between cells. Nat Cell Biol 9: 654-659, 2007.

11. Kosaka N, Iguchi H, Hagiwara K, Yoshioka Y, Takeshita F and Ochiya T: Neutral sphingomyelinase 2 (nSMase2)-dependent exosomal transfer of angiogenic microRNAs regulate cancer cell metastasis. J Biol Chem 288: 10849-10859, 2013

12. Nishida N, Nagahara M, Sato T, Mimori K, Sudo T, Tanaka F, Shibata K, Ishii H, Sugihara K, Doki Y, et al: Microarray analysis of colorectal cancer stromal tissue reveals upregulation of two oncogenic miRNA clusters. Clin Cancer Res 18: 3054-3070, 2012.

13. Bullock MD, Pickard K, Mitter R, Sayan AE, Primrose JN, Ivan C, Calin GA, Thomas GJ, Packham GK and Mirnezami AH: Stratifying risk of recurrence in stage II colorectal cancer using deregulated stromal and epithelial microRNAs. Oncotarget 6 : 7262-7279, 2015

14. Kijima T, Hazama S, Tsunedomi R, Tanaka H, Takenouchi H, Kanekiyo S, Inoue Y, Nakashima M, Iida M, Sakamoto K, et al: MicroRNA-6826 and -6875 in plasma are valuable noninvasive biomarkers that predict the efficacy of vaccine treatment against metastatic colorectal cancer. Oncol Rep 37: 23-30, 2017.

15. Livak KJ and Schmittgen TD: Analysis of relative gene expression data using real-time quantitative PCR and the $2^{-\Delta \Delta C \mathrm{~T}}$ method. Methods (San Diego, Calif.) 25: 402-408, 2001.

16. Wang C, Sun Y, Wu H, Yu S, Zhang L, Meng Y, Liu M, Yang H, Liu P, Mao X, et al: Elevated miR-483-3p expression is an early event and indicates poor prognosis in pancreatic ductal adenocarcinoma. Tumour Biol 36: 9447-9456, 2015.

17. Iizuka N, Oka M, Yamada-Okabe H, Nishida M, Maeda Y, Mori N, Takao T, Tamesa T, Tangoku A, Tabuchi H, et al: Oligonucleotide microarray for prediction of early intrahepatic recurrence of hepatocellular carcinoma after curative resection. Lancet 361: 923-929, 2003.
18. Liu M and Chen $\mathrm{H}$ : The role of microRNAs in colorectal cancer. J Genet Genomics 37: 347-358, 2010.

19. Vicinus B, Rubie C, Stegmaier N, Frick VO, Kölsch K, Kauffels A, Ghadjar P, Wagner M and Glanemann M: miR-21 and its target gene CCL20 are both highly overexpressed in the microenvironment of colorectal tumors: Significance of their regulation. Oncol Rep 30: 1285-1292, 2013

20. Ling H, Pickard K, Ivan C, Isella C, Ikuo M, Mitter R, Spizzo R, Bullock M, Braicu C, Pileczki V, et al: The clinical and biological significance of MIR-224 expression in colorectal cancer metastasis. Gut 65: 977-989, 2016.

21. Zhou J, Zhang M, Huang Y, Feng L, Chen $\mathrm{H}, \mathrm{Hu} \mathrm{Y}$, Chen $\mathrm{H}$, Zhang K, Zheng L and Zheng S: MicroRNA-320b promotes colorectal cancer proliferation and invasion by competing with its homologous microRNA-320a. Cancer Lett 356: 669-675, 2015.

22. Kim YK, Yu J, Han TS, Park SY, Namkoong B, Kim DH, Hur K, Yoo MW, Lee HJ, Yang HK and Kim VN: Functional links between clustered microRNAs: Suppression of cell-cycle inhibitors by microRNA clusters in gastric cancer. Nucleic Acids Res 37: 1672-1681, 2009.

23. Matsuzaki J and Suzuki H: Role of MicroRNAs-221/222 in digestive systems. J Clin Med 4: 1566-1577, 2015.

24. Chun-Zhi Z, Lei H, An-Ling Z, Yan-Chao F, Xiao Y, Guang-Xiu W,Zhi-Fan J, Pei-Yu P, Qing-Yu Z and Chun-Sheng K: MicroRNA-221 and microRNA-222 regulate gastric carcinoma cell proliferation and radioresistance by targeting PTEN. BMC Cancer 10: 367, 2010.

25. Tanaka R, Tomosugi M, Horinaka M, Sowa $\mathrm{Y}$ and Sakai T: Metformin Causes G1-phase arrest via down-regulation of MiR-221 and enhances TRAIL sensitivity through DR5 Up-regulation in pancreatic cancer cells. PLoS One 10: e0125779, 2015.

26. Qin J and Luo M: MicroRNA-221 promotes colorectal cancer cell invasion and metastasis by targeting RECK. FEBS Lett 588: 99-104, 2014.

27. Zhang C, Zhang J, Zhang A, Wang Y, Han L, You Y, Pu P and Kang C: PUMA is a novel target of miR-221/222 in human epithelial cancers. Int J Oncol 37: 1621-1626, 2010.

28. Zhao JJ, Chu ZB, Hu Y, Lin J, Wang Z, Jiang M, Chen $M$, Wang X, Kang Y, Zhou Y, et al: Targeting the miR-221-222/PUMA/BAK/BAX pathway abrogates dexamethasone resistance in multiple Myeloma. Cancer Res 75: 4384-4397, 2015.

29. Uozaki H, Morita S, Kumagai A, Aso T, Soejima Y, Takahashi Y and Fukusato T: Stromal miR-21 is more important than miR-21 of tumour cells for the progression of gastric cancer. Histopathology 65: 775-783, 2014.

30. Zhao L, Sun Y, Hou Y, Peng Q, Wang L, Luo H, Tang X, Zeng Z and Liu M: MiRNA expression analysis of cancer-associated fibroblasts and normal fibroblasts in breast cancer. Int J Biochem Cell Biol 44: 2051-2059, 2012.

31. Shimoda M, Principe S, Jackson HW, Luga V, Fang H, Molyneux SD, Shao YW, Aiken A, Waterhouse PD, Karamboulas C, et al: Loss of the Timp gene family is sufficient for the acquisition of the CAF-like cell state. Nat Cell Biol 16: 889-901, 2014.

32. Garofalo M, Di Leva G, Romano G, Nuovo G, Suh SS, Ngankeu A, Taccioli C, Pichiorri F, Alder H, Secchiero P, et al: $m i R-221 \& 222$ regulate TRAIL resistance and enhance tumorigenicity through PTEN and TIMP3 downregulation. Cancer Cell 16: 498-509, 2009.

33. Xu Q, Li P, Chen X, Zong L, Jiang Z, Nan L, Lei J, Duan W, Zhang D, Li X, et al: miR-221/222 induces pancreatic cancer progression through the regulation of matrix metalloproteinases. Oncotarget 6: 14153-14164, 2015. 